\title{
Evaluation of routine enteric pathogens in hospitalized patients: A Canadian perspective
}

\author{
KeVIN GOUGH MD, MiChelle Alfa PhD, GODFrey HardinG MD
}

\begin{abstract}
K GOUGH, M ALFA, G HARDING. Evaluation of routine enteric pathogens in hospitalized patients: A Canadian perspective. Can J Infect Dis 1996;7(3):197-202. Diarrhea is a frequently encountered problem in hospitalized patients. Since nosocomial spread of routine enteric pathogens such as Salmonella species, Shigella species, Campylobacter species and Escherichia coli O:157 H:7 seldom occurs, testing for these organisms in patients hospitalized for longer than three days has been questioned. The goal of this study was to determine the length of hospitalization preceding detection of routine enteric pathogens and Clostridium difficile cytotoxin, and to develop guidelines for enteric cultures from hospitalized patients. The enteric pathogens detected in 1991 were $\mathrm{C}$ difficile toxin $\mathrm{B}(+), 77 \%$; Campylobacter species, 10\%; Salmonella species, 9\%; E coli O:157 H:7, 3\%; and Shigella species, $1 \%$. For 1992, these numbers were $86 \%, 9 \%$, $3 \%, 2 \%$ and $0 \%$, respectively. None of the routine enteric pathogens isolated in 1991 or 1992 was detected in patients after their second day of hospitalization. Routine cultures for enteric pathogens on hospitalized patients were eliminated in February 1993, and physician ordering practices were monitored. With the exception of one campylobacter isolate per year, all routine enteric pathogens isolated in 1993 and 1994 were detected by the second day of hospitalization. Compliance with the changed protocol was $76 \%$ measured over a four-month period in 1993 and $74 \%$ over the year 1994 . Savings of $\$ 3,648.10$ were associated with rejecting 191 'inappropriate' specimens in 1994 . It was concluded that routine enteric cultures are unnecessary for patients hospitalized more than two days, and that appreciable financial savings can be achieved if revised protocols for processing stool cultures are instituted. However, when enteric protocol changes are in place compliance must be evaluated to ensure appropriate utilization.
\end{abstract}

Key Words: Clostridium difficile, Diarrhea, Enteric pathogens, Length of hospitalization, Nosocomial infection, Stool processing

\section{Évaluation des organismes pathogènes entériques habituels chez les patients hospitalisés : perspective canadienne}

RÉSUMÉ : La diarrhée est un problème fréquent chez les patients hospitalisés. Étant donné que la propagation nosocomiale des organismes pathogènes entériques comme Salmonella, Shigella, Campylobacter et Escherichia coli 0157H:7 survient rarement, le dépistage de ces organismes pathogènes chez les patients hospitalisés pendant plus de trois jours a été remis en question. L'objectif de cette étude était de déterminer la durée du séjour hospitalier précédant un dépistage des organismes pathogènes entériques courants et de la cytotoxine de Clostridium difficile et de mettre au point des directives de cultures entériques chez les patients hospitalisés. Les organismes pathogènes entériques décelés en 1991 étaient la toxine B(+) de C. difficile 77 \%; le genre Campylobacter $10 \%$, le genre Salmonella 9 \%, E. coli 0157H:7

voir page suivante

Departments of Medical Microbiology and Internal Medicine, University of Manitoba, and Department of Microbiology and Section of Infectious Diseases, St Boniface General Hospital, Winnipeg, Manitoba

Correspondence and reprints: Dr Michelle Alfa, Department of Microbiology, St Boniface General Hospital, 409 Taché Avenue, Winnipeg, Manitoba R2H 2A6. Telephone 204-237-2105, fax 204-237-6065, e-mail malfa@cc.umanitoba.ca

Received for publication October 10, 1995. Accepted February 14, 1996 


\begin{abstract}
$3 \%$ et le genre Shigella $1 \%$. Pour 1992, ces chiffres étaient de $86 \%, 9 \%, 3 \%, 2 \%$ et $0 \%$ respectivement. Aucun des organismes pathogènes entériques courants isolés en 1991 ou 1992 n'ont été décelés chez les patients après leur deuxième jour d'hospitalisation. Les cultures de routine pour dépistage des organismes pathogènes entériques chez les patients hospitalisés ont été éliminées en février 1993 et les pratiques médicales ont été surveillées. À l'exception d'un isolat par année de Campylobacter, tous les organismes pathogènes entériques isolés en 1993 et 1994 l'on été dès le deuxième jour d'hospitalisation. L'observance du protocole modifié a été évaluée à 76 \% sur une période de quatre mois en 1993 et à $74 \%$ au cours de 1994. Des économies de 3 648,10 \$ ont été associées au rejet de 191 spécimens insatisfaisants en 1994. Il en a été conclu que les cultures entériques de routine sont superflues chez les patients hospitalisés plus de deux jours et que des économies substantielles peuvent être obtenues par une révision des protocoles de cultures de selles. Il faut toutefois vérifier l'observance des nouveaux protocoles entériques.
\end{abstract}

$\mathrm{T}^{\mathrm{s}}$ he morbidity associated with diarrheal illnesses in both in-patient and out-patient settings is significant. A number of studies suggest that there are significant differences with respect to the infectious etiology in these two groups (1-4). While community acquired infectious diarrhea is often associated with Campylobacter species, Salmonella species, Shigella species, Escherichia coli 0:157 H:7, viral or parasitic infection, Clostridium difficile toxin-mediated enterocolitis appears to be a significant cause of nosocomial diarrheal illness (5).

The need to ensure appropriate, cost effective diagnostic testing has prompted many laboratories to reassess the microbiology services they offer (6-8). Robinson (9) has recently reviewed the rationale for cost effective laboratory medicine, and has identified the need to determine critically whether costly changes in technology actually benefit patient care. Processing of specimens in diagnostic laboratories often follows routine protocols that were developed many years ago, and the applicability of these approaches needs to be assessed on a regular basis. This is particularly true for stool specimens. Although stool cultures for routine enteric pathogens do not account for the bulk of diagnostic tests at our institution, they are among the top 10 tests requested, accounting for approximately $2 \%$ of the total specimens received or approximately 1000 specimens annually. Routine processing usually involves culture for routine enteric pathogens, irrespective of whether the specimen came from an in-patient or an outpatient.

A number of investigators have studied the utility of routine stool cultures in the evaluation of nosocomial diarrhea (2-4). A retrospective analysis of routine stool cultures, ova and parasite examinations, and $\mathrm{C}$ difficile toxin assay in the diagnosis of diarrhea in hospitalized patients has recently been reported by Siegel et al (2) from the University of Pennsylvania. Their data support the limited role of routine enteric pathogens as a cause of diarrhea in patients hospitalized for longer than three days, and suggest that substantial financial savings could result by eliminating routine stool cultures and ova and parasite examinations on these patients.

The aim of this study was to analyze retrospectively the etiology of infectious diarrhea in hospitalized patients in a Canadian tertiary care hospital. A protocol change was instituted to reduce inappropriate testing, and compliance with this new protocol was evaluated. Furthermore, the cost savings associated with instituting this protocol change were examined.

\section{PATIENTS AND METHODS}

Study design: A retrospective search was done at St Boniface General Hospital, Winnipeg, Manitoba, a 600-bed tertiary care teaching hospital with approximately 22,000 admissions annually (1994). The hospital serves primarily adult patients with active medical and surgical services including a 14-bed medical intensive care unit (ICU)/cardiac care unit, a 10-bed surgical ICU and a 10-bed neonatal ICU. The pediatric wards were officially closed in 1992; however, pediatric emergency room visits numbered 4911 in 1994 (12.4\% of all emergency room visits), and 6968 visits were made to the pediatric outpatient clinics that same year. There is a referral-based posttravel clinic incorporated into the Infectious Diseases clinics. All patients from whom enteric pathogens were isolated in 1991 and 1992 were identified, and computer records were checked to determine their date of admission. The date of collection of the diagnostic stool sample was verified, allowing determination of the number of days of hospitalization preceding pathogen detection.

Specimen collection: Stool samples were collected in sterile containers (no transport medium) from patients on the wards within the hospital. No specimens were received from sites outside of the hospital. Stool specimens were either processed upon receipt in the microbiology laboratory on the date of collection, or refrigerated at $4^{\circ} \mathrm{C}$ and processed within $12 \mathrm{~h}$.

Organism identification: Routine bacterial stool cultures were inoculated onto various selective and differential media including MacConkey agar, deoxycholate citrate agar, xyloselysine-deoxycholate agar and Selenite $\mathrm{F}$ broth and incubated aerobically at $35^{\circ} \mathrm{C}$ according to standard laboratory methods (10). MacConkey agar with sorbitol was added if a bloody stool was received or if analysis for E coli O: $157 \mathrm{H}: 7$ was specifically requested. Selenite $\mathrm{F}$ broth was subcultured to xylose-lysinedeoxycholate agar after overnight incubation at $35^{\circ} \mathrm{C}$. Enteric Gram-negative bacilli were identified using the API $20 \mathrm{E}$ (bioMerieux Vitek Inc, Missouri) and Microscan (Microscan, California) methodologies. Difco Laboratories (Michigan) antisera were used to group Salmonella species and Shigella species, and E coli O:157 H:7 serotyping was done using the Microscreen latex antigen detection kit (Mercia Diagnostics Ltd, Surrey, United Kingdom). Campylobacter species were cultured on campylobacter blood-free selective medium containing cefoperazone and amphotericin B (Lab M, Bury, United Kingdom). These plates were incubated at $42^{\circ} \mathrm{C}$ for $48 \mathrm{~h}$ in an environment containing $85 \%$ nitrogen, $10 \%$ carbon dioxide and $5 \%$ oxygen. If analysis for yersinia was requested, stool was in- 
TABLE 1

Incidence of enteric pathogens by year of isolation

\begin{tabular}{|c|c|c|c|c|}
\hline & \multicolumn{4}{|c|}{ Year tested } \\
\hline & 1991 & 1992 & 1993 & 1994 \\
\hline \multicolumn{5}{|l|}{ Routine enteric pathogens } \\
\hline Total tested & 1445 & 1504 & 934 & 728 \\
\hline Number positive (\% of total positive stools) & $63(23 \%)$ & $30(14 \%)$ & $21(17 \%)$ & $45(25 \%)$ \\
\hline \multicolumn{5}{|l|}{ Pathogen } \\
\hline Campylobacter species & $28(10 \%)$ & $20(9 \%)$ & $10(8 \%)$ & $23(13 \%)$ \\
\hline Salmonella species & $25(9 \%)$ & $7(3 \%)$ & $4(3 \%)$ & $13(7 \%)$ \\
\hline Escherichia coli O:157 H:7 & $8(3 \%)$ & $3(2 \%)$ & $5(4 \%)$ & $3(2 \%)$ \\
\hline Shigella species & $2(1 \%)$ & $0(0 \%)$ & $2(2 \%)$ & $6(3 \%)$ \\
\hline \multicolumn{5}{|l|}{ Clostridium difficile toxin B } \\
\hline Total tested & 1249 & 1459 & 931 & 1072 \\
\hline Number positive (\% of all positive stools) & 207 (77\%) & $184(86 \%)$ & $104(83 \%)$ & $138(75 \%)$ \\
\hline
\end{tabular}

oculated onto Cefsulodin-Irgasan-Novobiocin agar (Difco Laboratories) and incubated at $30^{\circ} \mathrm{C}$ for $48 \mathrm{~h}$. Aeromonas species were not routinely sought, but if requested a blood agar plate was inoculated and incubated at $37^{\circ} \mathrm{C}$ for $48 \mathrm{~h}$. Suspicious colonies (oxidase-positive, beta-hemolytic) were further identified biochemically. $\mathrm{C}$ difficile colitis was diagnosed by detection of toxin B-induced cytopathic effect using human foreskin fibroblast cells in a conventional microtitre cell culture method. Specificity of the cytopathic effect was confirmed by neutralization with Bartels $\mathrm{C}$ difficile antitoxin (Baxter Diagnostics Inc, Illinois).

Protocol change: Based on the 1991 and 1992 data obtained, a change in protocol for routine enteric pathogens was undertaken. If the patient had been hospitalized for more than three days, the stool sample was not processed for routine enteric pathogens. Notification of the change in protocol for stool processing was circulated to all wards, physicians and nursing personnel by a newsletter in February 1993. For all stool specimens received in the laboratory after that date, the duration of patient hospitalization before sampling was determined. An aliquot of any stool not processed was kept for three days in pre-reduced anaerobically sterilized (PRAS) transport medium at $4^{\circ} \mathrm{C}$, and the ward was notified that the sample had not been processed for routine enteric pathogens. The aliquot was processed if the physician contacted the laboratory over the next three days with additional information that would warrant routine testing; otherwise the stored specimen was discarded. All stool samples were processed for $\mathrm{C}$ difficile toxin $\mathrm{B}$ if requested.

Compliance evaluation: Compliance with the protocol change was evaluated by reviewing data for a four-month period during 1993 and for the entire year 1994. Compliance was assessed by determining the total number of stool samples submitted, the number of specimens not processed routinely according to the protocol (ie, rejected) and the number of stool specimens for which additional information was provided resulting in processing of the stored specimen. The cost savings associated with specimens rejected during 1994 were calculated based on internal supplies and labour costs.

\section{RESULTS}

During 1991, a total of 1445 stool specimens was received for routine enteric pathogen testing and 1249 for $\mathrm{C}$ difficile toxin testing (Table 1). Of this combined total, 270 (10\%) were positive for either routine enteric pathogens or $\mathrm{C}$ difficile toxin B. The majority of these enteric infections (77\%) were due to toxigenic $\mathrm{C}$ difficile. Other isolates included Campylobacter species (10\%), Salmonella species (9\%), E coli 0:157 H:7 (3\%) and Shigella species (1\%). Similar results were obtained for 1992 (Table 1), with C difficile toxin detected in $86 \%$ of all positive stools. None of the patients with stools positive for routine enteric pathogens in 1991 or 1992 had been in hospital for more than two days before pathogen detection (Figure 1).

The data for 1993 and 1994, which reflect the protocol change, revealed that in 1993, a total of 934 specimens was submitted for routine enteric culture and 931 for $\mathrm{C}$ difficile testing. There were 125 (7\%) total positive results of which 104 (83\%) were due to $\mathrm{C}$ difficile cytotoxin B (Table 1). All routine enteric pathogens were isolated from patients who had been in hospital for less than three days, with the exception of a single isolate of Campylobacter species isolated from a patient who had been in hospital four days before sampling (Figure 2). Review of this patient's medical record revealed an elderly man with Alzheimer's disease who was admitted from home because his wife was no longer able to care for him in that setting. He was noted to be incontinent of both urine and formed stool at home and in hospital. There was no history of diarrhea, and the stool was submitted to the laboratory on day 4 of hospitalization.

In 1994, a total of 728 specimens was received for routine enteric culture and 1072 for $\mathrm{C}$ difficile toxin B testing. There were $183(10 \%)$ total positive results, of which 138 (75\%) were $\mathrm{C}$ difficile toxin-positive (Table 1). During that year, all routine enteric pathogens were isolated from patients who had been hospitalized for less than two days, with the exception of another single isolate of Campylobacter species isolated after four days of hospitalization (Figure 2). This patient was readmitted to hospital with a peripancreatic abscess and infected 


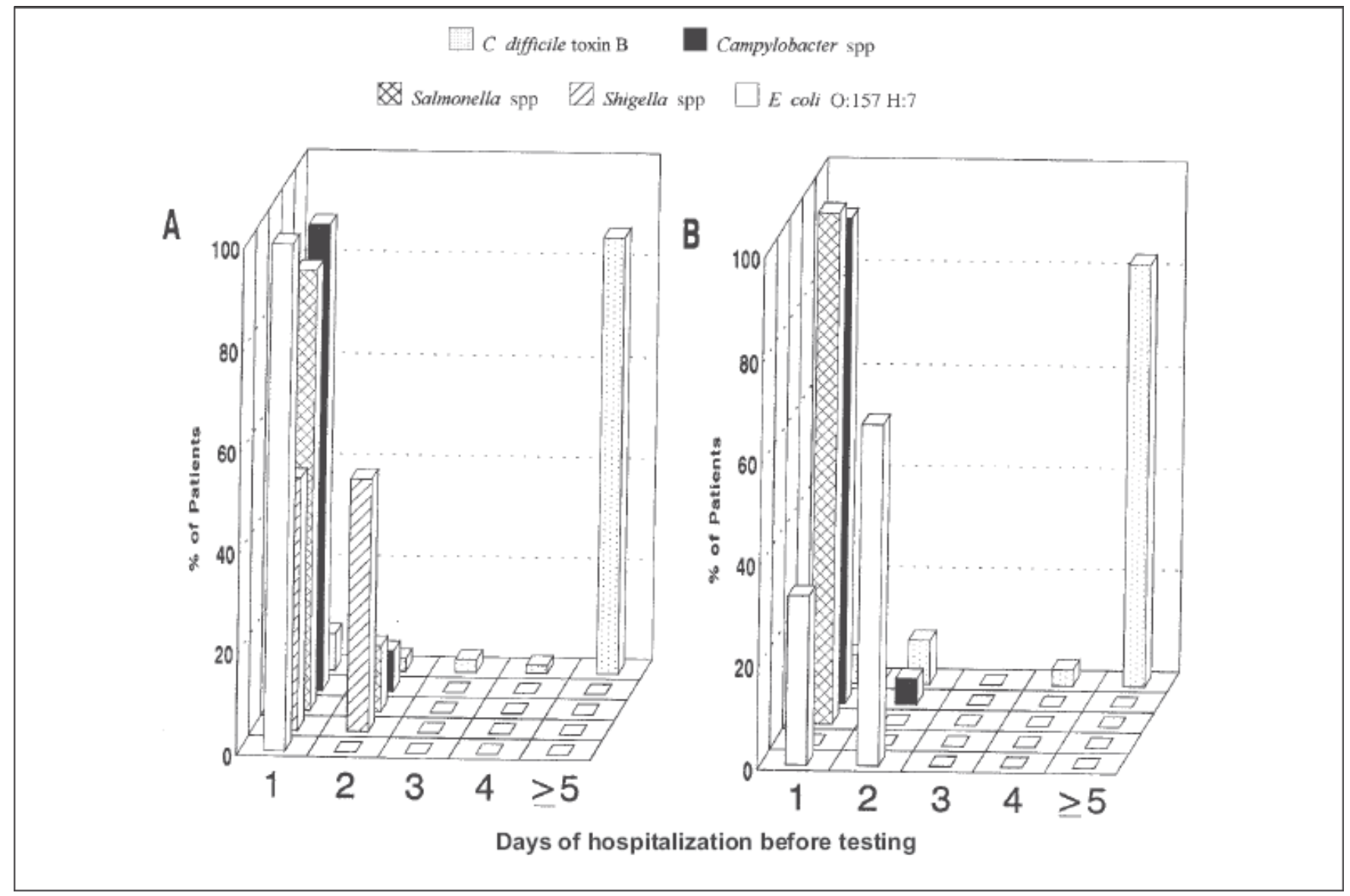

Figure 1) Length of hospitalization before detection of enteric pathogens for patients having stool cultures submitted because of diarrhea under the old protocol. A 1991; B 1992

pseudocysts six weeks after an episode of acute pancreatitis. There was no history of diarrhea on admission. He developed diarrhea on the third day of hospitalization. Nasogastric tube feeds were started on this day and he had been on ampicillin, gentamicin and metronidazole for two days. $\mathrm{C}$ difficile toxin $\mathrm{B}$ was negative, and the diarrhea had resolved by day 10 of hospitalization.

Compliance data revealed that, for a three-month period in 1993, 39 (24\%) of 161 stools submitted were rejected yielding a compliance rate of $76 \%$. For the entire year 1994, 191 of 728 stools submitted (26\%) were rejected, yielding a compliance rate of $74 \%$. Since the change in protocol, only one stool sample was processed after initially being rejected. In this case, the physician provided additional information that resulted in processing of the stool for routine enteric pathogens. No enteric pathogens were detected in this stool sample. The practice of holding an aliquot of stool in PRAS transport medium pending further information from the ordering physician is no longer done. In the authors' experience, this practice did not result in the subsequent isolation of enteric pathogens.

\section{DISCUSSION}

Diarrhea is a frequent occurrence in hospitalized patients (11). Nosocomial outbreaks of diarrhea account for $21 \%$ of all 223 nosocomial outbreaks reported to the Centers for Disease
Control and Prevention from 1956 to 1979 (12). It has been suggested to be the most common nosocomial infection in certain patient populations (13), and appears to predispose significantly to other nosocomial infections such as urinary tract infections (14). Overall rates range from 2.3 to 4.1 illnesses/100 pediatric ward admissions $(13,15)$ and from $7.7 / 100$ admissions to $41 \%$ of adult ICU patients $(13,16)$.

The etiology of diarrhea in the hospitalized patient may be either infectious or noninfectious. It is important to appreciate that testing of stool from hospitalized patients for routine enteric pathogens is warranted where clinically or epidemiologically indicated (eg, onset of symptoms before admission, outbreak situations, significant history of exposure, follow-up cultures, etc). At our institution in 1994, there were 728 tests performed for routine enteric pathogens and 1072 tests for C difficile toxin B from patients with diarrhea. Our data suggest that culturing stool for Salmonella, Shigella, Yersinia or Campylobacter species in patients who have been in hospital for more than two days before the onset of diarrhea is of low yield. Only two isolates were recovered from 1662 specimens after the second day of admission. Although use of transport media and shorter transit times (less than $1 \mathrm{~h}$ ) may improve recovery, our data are in agreement with similar retrospective and prospective analyses (2-4) and suggest that stool cultures from adult in-patients should not be processed for routine en- 


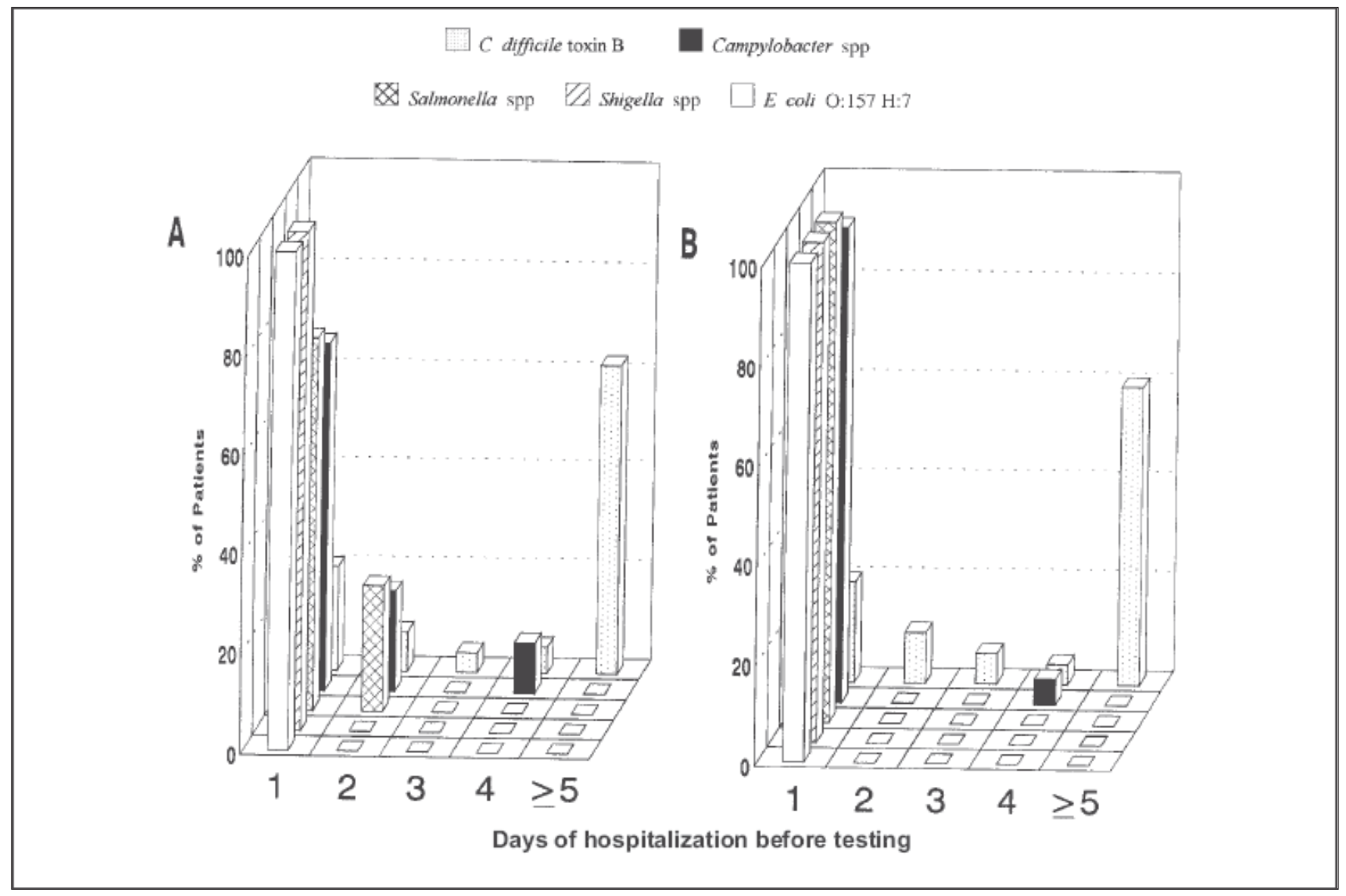

Figure 2) Length of hospitalization before detection of enteric pathogens for patients having stool cultures submitted because of diarrhea under the new protocol. A 1993; B 1994

teric pathogens after day 3 of hospitalization unless there are clear indications for doing so.

Campylobacter species were isolated from a single patient in each of 1993 and 1994 after more than two days of hospitalization. These patients were likely infected before hospitalization, and since the incubation period can vary from one to seven days, it is not surprising that the organism was detected on the fourth hospital day in each case. There were no reports of nosocomial outbreaks of Campylobacter species at the time each patient was hospitalized. The absence of diarrhea in the first case may represent early or attenuated disease. In the second case, the self-limiting illness resolved clinically by day 10 of hospitalization. These two samples represent $0.12 \%$ of all stool specimens received for routine enteric culture during this two-year period and $0.65 \%$ of such positives.

Our data also support the significant role that $\mathrm{C}$ difficile plays in nosocomial diarrhea. The majority of positive stool examinations in each year surveyed yielded $\mathrm{C}$ difficile toxin $\mathrm{B}$, which in most cases was detected after five days of hospitalization. There were, however, 23 toxin-positive stools $(11 \%$ of all positives) from patients hospitalized for three days or less in 1992, 25 (20\%) such stools in 1993 and 29 (16\%) in 1994. Although often associated with hospital acquisition, $\mathrm{C}$ difficile has been shown to cause both nosocomial and community acquired diarrhea (17). Therefore, examination of stool speci- mens for $\mathrm{C}$ difficile should be undertaken when requested, regardless of the length of hospitalization at the time of sample collection.

Protocols that have been in place for years are often difficult to change, making compliance evaluation a critical step whenever changes are introduced. We found that over the four-month evaluation period in 1993, $24 \%$ of samples were rejected based on protocol changes. For the year 1994, 26\% were rejected based on this protocol. These numbers correspond to compliance rates of $76 \%$ and $74 \%$, respectively. Our results are similar to those of Fan et al (3), who rejected 30\% of specimens over the 10 months following a protocol change at their institution. Compliance of hospital personnel to changes in protocol was also examined by Alfa et al (18) after instituting a new protocol for the collection of blood cultures. They found a compliance rate of $60 \%$ to $74 \%$ within one month of starting the new protocol. As suggested by Alfa et al, simple graphic aids that clearly summarize the change can help in the retraining process. The lack of an appreciable change in compliance rate from 1993 to 1994 emphasizes the need to have ongoing assessment of compliance to ensure adequate retraining.

In the current economic climate of budgetary constraints and shrinking resources, it is necessary that laboratories become increasingly cost efficient and financially responsible. One potential cost saving method available to the laboratory 
is that of limiting test availability based on the utility of a particular test procedure. With respect to stool cultures then, it is reasonable that accurate, cost effective methods for diagnosis should focus on the most likely etiologies, with further extensive testing reserved for cases where limited testing is negative or identifiable risk factors for other etiologies exist. If inappropriate testing can be eliminated or at least significantly reduced, there exists the potential for significant cost saving.

At our institution, enteric cultures are estimated to cost $\$ 19.10$ (including labour) per examination when no pathogens are isolated. The savings associated with rejecting 191 'inappropriate' specimens in 1994 was \$3,648.10. Further savings can be appreciated by considering the impact that the change in protocol has had on physician ordering practices. There has been a significant reduction in the total number of requests for routine stool cultures from 1504 (1992) to 934 (1993) to 728 (1994), suggesting compliance with the

\section{REFERENCES}

1. Gilligan PH. Diarrheal disease in the hospitalized patient. Infect Control 1981;7:607-9.

2. Siegel DL, Edelstein PH, Nachamkin PH. Inappropriate testing for diarrheal diseases in the hospital. JAMA 1990;263:979-82.

3. Fan K, Morris AJ, Reller LB. Application of rejection criteria for stool cultures for bacterial enteric pathogens. J Clin Microbiol 1993;31:2233-5.

4. Barbut F, Leulan P, Antoniotti G, Collignon A, Sedallion A, Petit JC. Value of routine stool cultures in hospitalized patients with diarrhea. Eur J Clin Microbiol Infect Dis 1995;14:346-9.

5. Gilligan PH, McCarthy LR, Genta VM. Relative frequency of Clostridium difficile in patients with diarrheal disease. J Clin Microbiol 1981;14:26-31.

6. Bartlett RC, Mazens-Sullivan M, Tetreault JZ, Lobel S, Nivard J. Evolving approaches to management of quality in clinical microbiology. Clin Microbiol Rev 1994;7:55-88.

7. Morris AJ, Wilson ML, Mirrett S, Reller LB. Rationale for selective use of anaerobic blood cultures. J Clin Microbiol 1993;31:2110-3.

8. Murray PR, Traynor P, Hopson D. Critical assessment of blood culture techniques: analysis of recovery of obligate and facultative anaerobes, strict aerobic bacteria, and fungi in aerobic and anaerobic blood culture bottles. J Clin Microbiol 1992;30:1462-8.

9. Robinson A. Rationale for cost-effective laboratory medicine. Clin Microbiol Rev 1994;7:185-99.

10. Balows A, Hausler WJ, Hermann KL, Isenberg HD, Shadomy HJ. changed protocol. Although the number of beds decreased during this period (808 to 683 to 632 ), as did the number of admissions $(24,350$ to 21,997 to 21,892$)$, this alone is not likely to account for the reduction in routine culture requests. For example, the period from 1992 to 1993 saw a 9.7\% reduction in admissions, but a $37.9 \%$ reduction in test requests.

\section{CONCLUSION}

We recommend that routine culture for enteric pathogens from patients hospitalized for more than two days should be eliminated. Only $\mathrm{C}$ difficile toxin testing should be performed on specimens from these patients unless there are clinical or epidemiological indications to test for routine bacterial pathogens or parasites. This approach will likely result in appreciable cost savings to the laboratory in terms of both labour and materials, without compromising patient care. Compliance evaluation and strategies to improve poor compliance are crucial aspects of any major protocol change.

Manual of Clinical Microbiology. Washington: American Society for Microbiology, 1991.

11. Guerrant RL, Bobak DA. Nausea, vomiting, and noninflammatory diarrhea. In: Mandell GL, Bennett JE, Dolin R, eds. Principles and Practice of Infectious Diseases, 4th edn. New York: Churchill Livingstone, 1995:970.

12. Stamm WE, Weinstein RA, Dixon RE. Comparison of endemic and epidemic nosocomial infections. Am J Med 1981;70:393-7.

13. Lima N, Searcy M, Guerrant R. Nosocomial diarrhea rates exceed those of other nosocomial infections on ICU and pediatric wards [Abst 1050]. 26th Interscience Conference on Antimicrobial Agents and Chemotherapy, New Orleans, September 28 to October 1, 1986.

14. Lima NL, Guerrant RL, Kaiser DL, et al. Nosocomial diarrhea: a possible risk factor for nosocomial infections. Clin Res 1988;36:580. (Abst)

15. Welliver RC, McLaughlin S. Unique epidemiology of nosocomial infection in a children's hospital. Am J Dis Child 1984;138:131-5.

16. Kelly WJ, Patrick MR, Hilman KM. Study of diarrhea in critically ill patients. Crit Care Med 1983;1:7-9.

17. McFarland LV, Mulligan ME, Kwok RYY, Stamm WE. Nosocomial acquisition of Clostridium difficile infection. N Engl J Med 1989;14:204-10.

18. Alfa M, Sanche S, Roman S, Fiola Y, Lenton P, Harding G. Continuous quality improvement for introduction of automated blood culture instrument. J Clin Microbiol 1995;33:1185-91. 


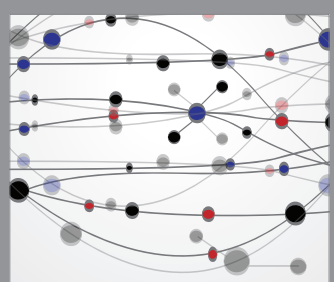

The Scientific World Journal
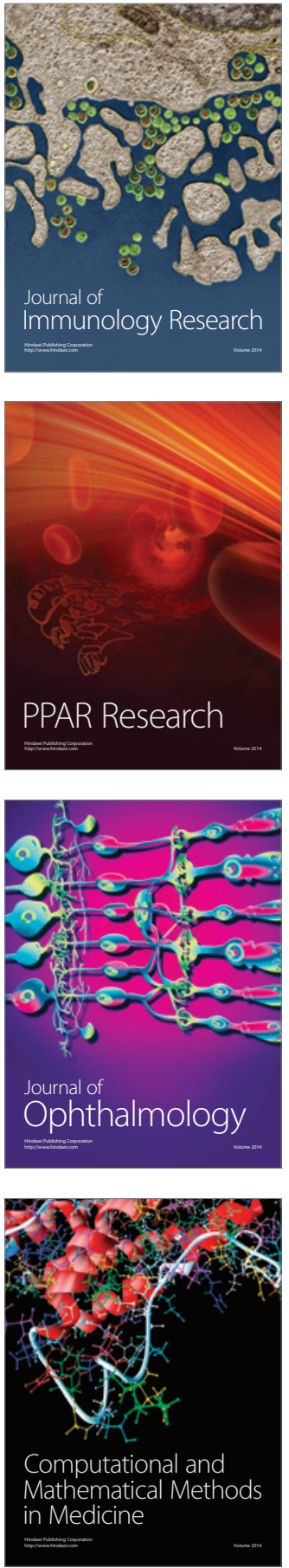

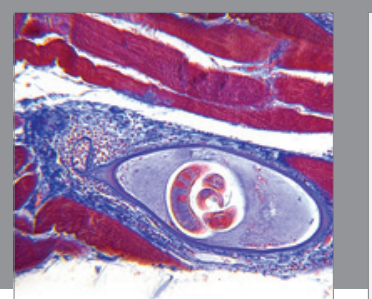

Gastroenterology Research and Practice

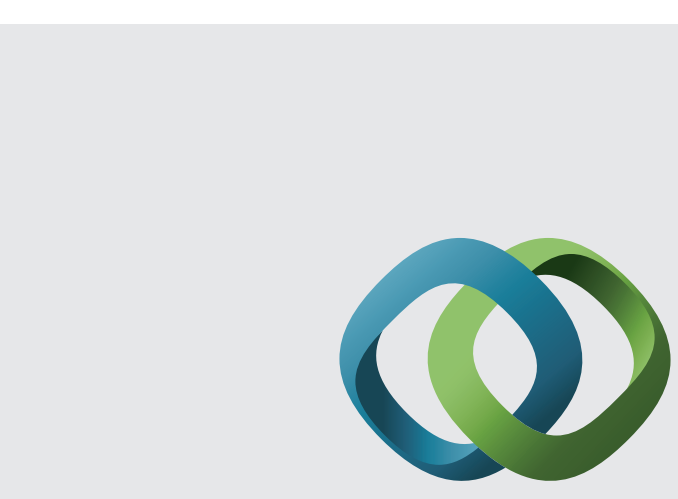

\section{Hindawi}

Submit your manuscripts at

http://www.hindawi.com
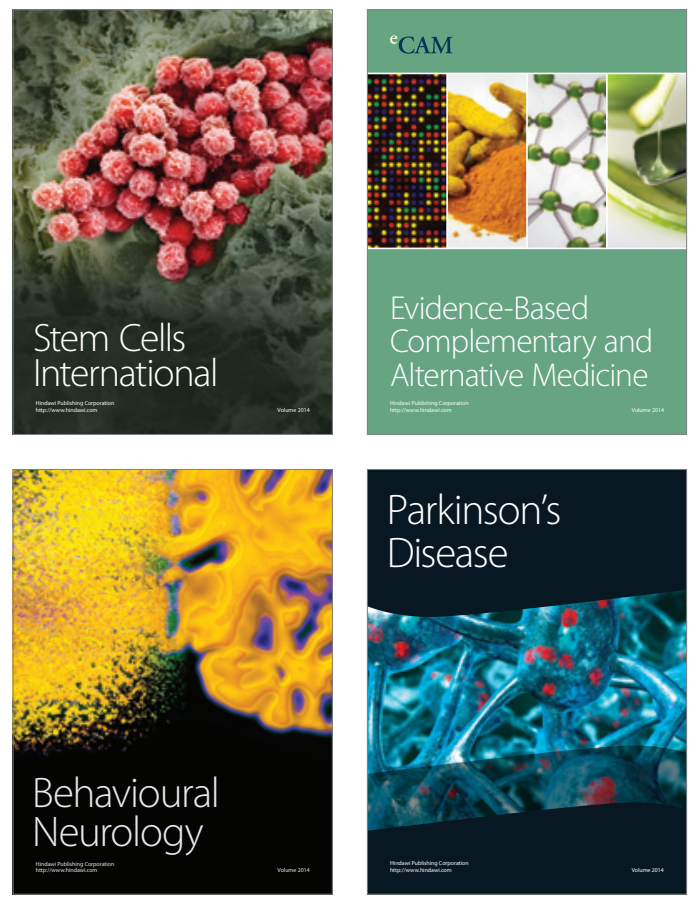
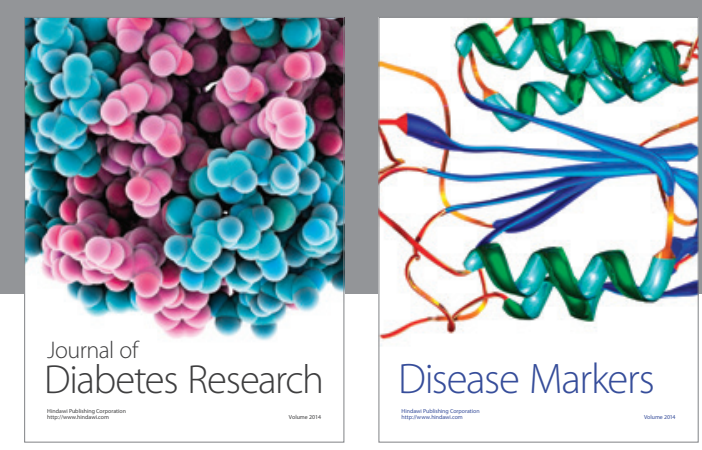

Disease Markers
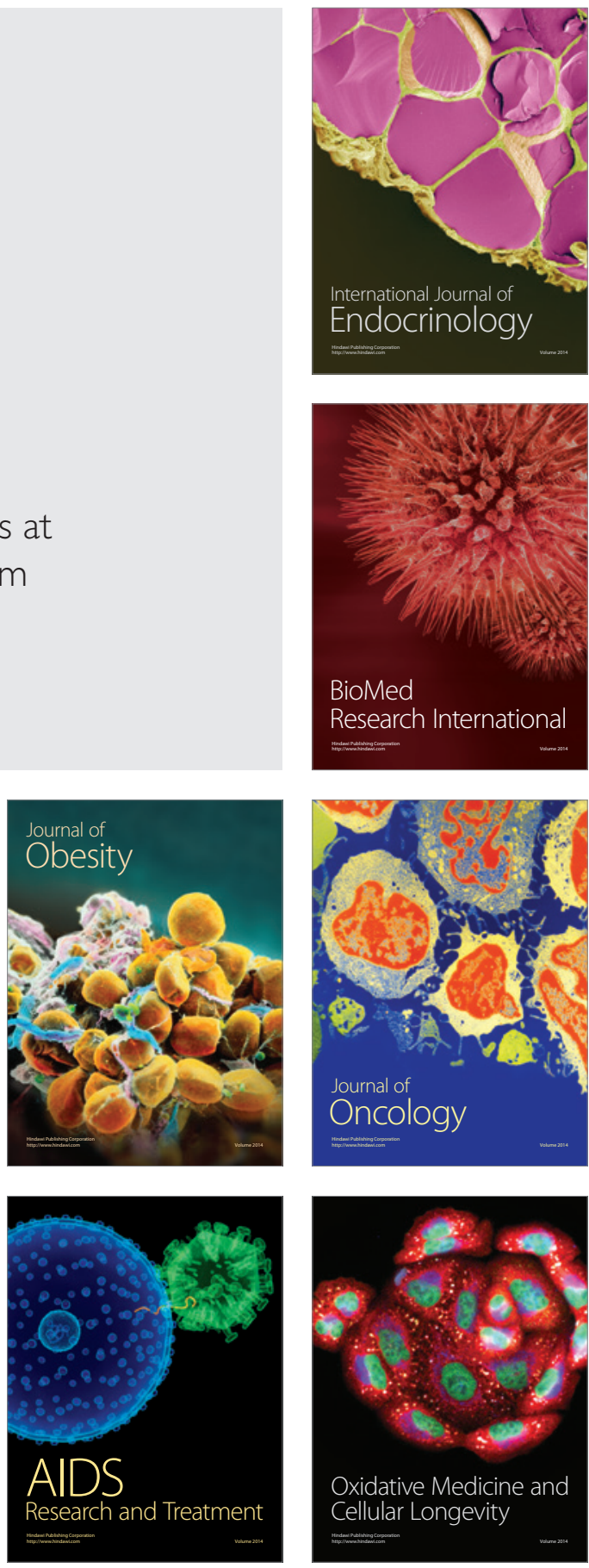